\title{
PEMODELAN DAN SIMULASI MICRORING RESONATOR DENGAN VARIASI KOPLING SEBAGAI SENSOR DAN PERANGKAT TELEKOMUNIKASI
}

\author{
Muhammad Zakaria $^{1}$; Lilik Hasanah ${ }^{1 *}$; Endi Suhendi ${ }^{*}$ \\ ${ }^{1)}$ Departemen Pendidikan Fisika, FPMIPA, Universitas Pendidikan Indonesia \\ Jl. Dr. Setiabudhi No. 229, Bandung dan 40154 \\ *Penulis Penanggungjawab. Email : zackmuhammadzakaria@gmail.com
}

\begin{abstract}
ABSTRAK
Untuk memperluas dan menghasilkan kualitas sensor yang baik dari Microring Resonator salah satu objek yang dapat divariasikan ialah kopling dalam devais Microring Resonator. Variasi kopling yang gunakan $0.25,0.3$, 0.5, 0.7. untuk luas sensing dapat dilihat pada FSR (Free Spectral Range) dan kualitas sensor dapat dilihat pada FWHM (full width half maksimum) sebagai parameter sensor dan perangkat telekomunikasi. FSR tidak dipengaruhi oleh kopling hanya dipengaruhi oleh jari-jari dan panjang gelombang. Dengan panjang gelombang yang digunakan 1300 dan 1350. FSR terbesar didapat pada nilai 1350. Kualitas sensor yang kita lihat pada FWHM. FWHM terbesar didapat pada 1350 (panjang gelombang) dan 0.7 lebar koplingnya.
\end{abstract}

Kata kunci: Microring Resonator, FSR, FWHM, Finesse Q-Factor

\begin{abstract}
In order to improve the performace of microring resonator, the object that can be varied is the coupler in the microring resonator device. The values of the coupler that varied is $0.25,0.3,0.5$ and 0.7 in nanometer. For the sensing range of the device can be observed in the FSR (Free Spectral Range) and the sensor quality can be observed in FWHM (full width half maximum) as the sensor's parameter and communication device. The FSR was not affected by the coupler but by the radius and the wavelength. In this paper the wavelength that is used are 1300 and
\end{abstract}


1350. The highest FSR obtained at the 1350 wavelength. The sensor quality is at best when the coupler is $0.7 \mathrm{~nm}$ with 1350 wavelength.

Keywords : Microring Resonator, FSR, FWHM, Finesse Q-Factor

\section{Pendahuluan}

Microring Resonator merupakan suatu devais yang sedang banyak di kembangkan pada aplikasi sensor optik maupun aplikasi sistem telekomunikasi. Pada aplikasi sistem sensor optik Microring Resonator merupakan salah satu devais yang memiliki potensi yang sangat besar karena Microring Resonator dapat menghasilkan sensitivitas yang tinggi dengan biaya fabrikasi yang murah (Mohammad A. dkk. 2015).

Selain pada Sistem sensor optik Microring Resonator juga dapat di gunakan pada sistem Telekomunikasi, pada sistem telekomunikasi Microring Resonator dapat di gunakan untuk meningkatkan kecepatan pengiriman data dan penerimaan data, Microring Resonator juga dapat di jadikan sebuah terminal dan berfungsi dalam penggabungan sinyal untuk memperoleh daya dan kecepatan daya (baud rate) yang lebih besar dalam transmisi berkapasitas tinggi (Heebner, J. Dkk. 2004).

Dalam penggunaan Microring Resonator di butuhkan laser, di karenakan laser memiliki spectrum yang sangat kecil sehingga dapat meminimalkan dispersi yang terjadi. Sedangkan bandwith yang besar dapat memperbesar nilai kecepatan data yang berefect pada kecepatan pengiriman dan penerimaan data.
Hal-hal yang mempengaruhi sistem telekomunikasi yang baik adalah panjang gelombang sumber yang di gunakan, waktu tanggapan yang pendek agar menghasilkan bandwith yang besar dan dapat menghasilkan laju band raute yang tinggi. (Isnawati, A. dkk. 2009)

Pembuatan devais Microring Resonator telah banyak dilakukan sebelumnya, baik untuk sistem sensor optik maupun sistem Telekomunikasi. Telah banyak peneliti yang langsung membuat Microring Resonator tanpa mempertimbangkan hasil yang akan di dapat nantinya.

Pada penelitian kali ini akan di lakukan perancangan dan pemodelan yang berupa sebuah aplikasi untuk mempermudah pembuatan Microring Resonator, sehingga untuk kedepannya para peneliti akan dapat lebih mudah dalam memprediksi dan membuat Microring Resonator yang akan di buatnya.

Aplikasi yang akan di gunakan untuk membuat perhitungan Microring Resonator ialah aplikasi MATLAB. MATLAB ialah suatu aplikasi pemodelan yang dapat kita buat untuk mempermudah perhitungan, untuk mendapatkan hasil yang diinginkan.

Pada pembuatan Microring Resonator kita memerlukan banyak parameterparameter penentu akan tetapi pada penelitian kali ini hanya akan 
mengambil beberapa parameter yang akan berguna untuk sistem sensor optik dan sistem telekomunikasi. Beberapa hasil dari parameter yang akan berguna untuk sistem sensor optik dan sistem telekomunikasi seperti Free Spectral Range ( FSR ), Full Width Half Maximum ( FWHM) ,Finesse Dan Q-Faktor yang dimana semua hasil parameter tersebut akan berguna pada kegunaan sistem sensor optik dan sistem telekomunikasi.

Pada penelitian kali ini juga akan di bantu menggunakan aplikasi komersial yaitu CST ( Computer Simulation Technology), pada aplikasi komersial ini Microring resonator dibentuk secara 3D. Microring yang dibentuk di sesuaikan dengan parameter-parameter yang telah di tentukan.

Aplikasi CST dapat digunakan untuk percepatan partikel, percepatan gelombang, dan berbagai aplikasi yang menggunakan frekuensi, baik pada frekuensi rendah maupun pada frekuensi yang tinggi.

Microring Resonator merupakan suatu devais perangkat yang terintegrasi optik dengan struktur yang sangat mudah di bentuk, pada pembentukan Microring Resonator ini mengunakan perangkat pemandu gelombang dengan menambahkan serta menyusun pemandu gelomban yang berbentuk Ring sesuai dengan karakteristik dan kebutuhan.

Terdapat banyak jenis sensor Microring Resonator. Pada dasarnya Sensor Microring terdiri dari satu Microring Resonator dan satu Waveguide atau pemandu gelombang dilihat pada gambar 1 dan gambar 2 memperlihatkan Microring Resonator dengan 2 waveguide.

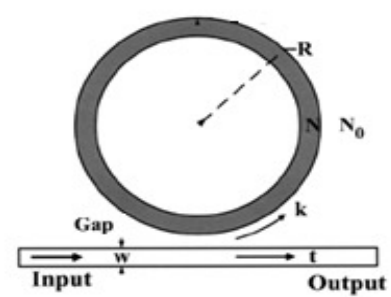

Gambar 1. Microring Resonator dengan satu waveguide.

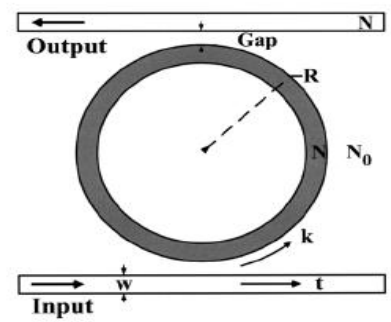

Gambar 2. Microring Resonator dengan 2 waveguide

Pada Microring Resonator kali ini akan menggunakan jenis Single Microring Resonator (SMR), Single Microring Resonator merupakan salah satu jenis dari filter optik Microring Resonator yang paling sederhana Struktur ini menggunakan satu buah ring dengan jari-jari ( $\mathrm{R}$ ) tertentu dan dikopling dengan dua buah pemandu gelombang yang berbentuk lurus. (Apriyadi D .2006)

Pada Microring Resonator yang merupakan penyebab berubahnya nilai sensor berada pada indeks bias suatu bahan. Sinar yang masuk melalui waveguide terjadi perubahan transmisi cahaya yang menyebar ke pada Microring. Pada microring Resonator terdapat 2 cara pemantauan parameter yang berbeda, pertama 
pergeseran panjang gelombang dan perubahan intensitas cahaya. Kedua perubahan intensitas cahaya yang dikarenakan perbedaan indeks bias antara pemandu gelombang dan Microring Resonator, dan resonansi dan panjang gelombang dari cahaya yang ditembakan.

\section{Metode Penelitian}

Pada tahapan ini di lakukan pemodelan dan perancangan Microring Resonator, dengan Jari-jari yang telah di tentukan sebesar 7mikrometer. dengan bahan yang di gunakan ialah InGaASP/Inp yang memiliki indeks bias sebesar 3,34, Variasi kopling yang di gunakan ialah 0,25. 0,3. 0,5. 0,7. Dan panjang gelombang yang di gunakan ialah dari 1300 - 1350 mikrometer.

\begin{tabular}{lll}
\hline No & Parameter & \multicolumn{1}{c}{ Nilai } \\
& Microring & \\
& Resonator & \\
& & \\
\hline 1 & Indeks bias & 3,34 \\
& & \\
& & 7 micrometer \\
\hline 2 & Jari-jari & $\left(\mathrm{K}_{1}=\mathrm{K}_{2}=0.25\right.$, \\
& & $0.3, \quad 0.5, \quad$ dan \\
& Kopling & $0,7) /$ mm \\
& & 1,30 dan 1,35 \\
& & mikrometer \\
\hline 4 & Panjang & \\
& Gelombang &
\end{tabular}

Setelah mengetahui parameterparameter yang akan di gunakan. Di lanjutkan dengan mencari hasil yang di perlukan dalam penggunakan Microring Resonator. Pertama mencari FSR menggunakan rumus

$$
F S R=\frac{\lambda^{2}}{N_{E f f}(2 \pi R)}(1)
$$

Dengan

$\lambda=$ Panjang gelombang

Neff $=$ Indeks bias relatif

$\Pi=3,14$

$\mathrm{R}=$ Jari - jari Microring.

Dimana FSR ( Free Spectral Range) dapat di definisikan sebagai lebar daerah pass band yang di hasilkan oleh filtering Microring Resonator ( Manggolo dkk.2011). Tahapan ke dua kita akan menggunakan FWHM (Full Width Half Maximum) dimana FWHM merupakan besar jarak antara dua buah frekuensi pada grafik transmitansi. Nilai bandwidth resonator di berikan oleh full-width at Half Maximum ( FWHM). Nilai Bandwith di ukur ketika puncak berada pada -3db dan berada pada daerah frekuensi kerja (Sadegh A, dkk 2015). Untuk FWHM dapat dirumuskan dengan :

$$
F W H M=\frac{K^{2} \lambda^{2}}{\pi L N_{E f f}}(2)
$$

Dengan :

$\lambda=$ Panjang gelombang

Neff $=$ Indeks bias relatife

$\Pi=3,14$

$\mathrm{R}=$ Jari - jari Microring 
$\mathrm{K}=$ Lebar kopling microring dengan pemandu gelombang

$\mathrm{L}=$ panjang pemandu gelombang

Setelah mendapatkan FSR dan FWHM dimulai lah kita akan mencari Finesse dari Microring Resonator. Finesse ini dapat di definisikan sebagai rasio antara nilai FSR dengan nilai FWHM, persamaan Finesse di nyatakan sebagai berikut :

$$
F=\frac{F S R}{F W H M}
$$

\section{Dengan}

FSR $=$ Free Spectral Range

$\mathrm{F}=$ Finesse

FWHM $=$ Full Width at Half Maximum

Quality Factor. Quality Faktor / Q-fak merupakan kualitas kemampuan suatu filter menyeleksi panjang gelombang tertentu. Nilai Q fac memiliki hubungan dengan Frekuensi kerja dan bandwith single Microring Resonator. $\mathrm{Q}$ factor dapat di tentukan dengan menghitung perbandingan antara Frekuensi kerja dengan bandwith.(Syah H.S.D, dkk 2014). Qfak dapat di rumuskan sebagai berikut

$$
Q=\frac{N_{e f f} L}{\lambda} F
$$

$\lambda=$ Panjang gelombang

Neff $=$ Indeks bias relatife

$$
\begin{aligned}
& \mathrm{L} \quad=\text { Panjang pemandu } \\
& \text { gelombang } \\
& \mathrm{F}=\text { finesse }
\end{aligned}
$$

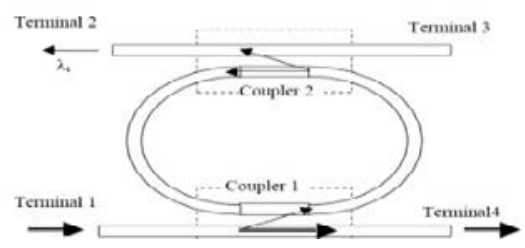

Gambar 3. Single Microring

Resonator

\section{Hasil Dan Pembahasan}

Perhitungan FSR dapat di cari dengan memasukan parameter pada tabel 1 ke dalam Persamaan (1). Pada hasil perhitungan FSR dapat di ketahui bahwa FSR hanya di pengaruhi oleh jari-jari dan panjang gelombang yang di gunakan di Microring Resonator

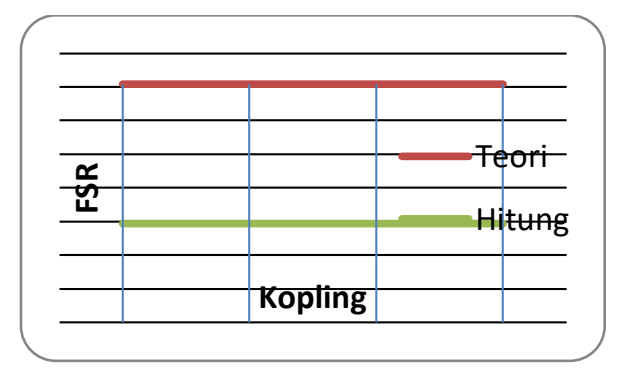

Gambar 4. Hasil FSR dengan panjang gelombang 1300 micrometer

Pada gambar 4 hasil FSR dengan panjang gelombang 1300 micrometer ini kita dapat melihat dengan hasil teori untuk kopling 0.25, 0.3, 0.5, 0.7 di dapatkan nilai FSR sebesar 11.5, Tetapi dengan perhitungan matlab di dapatkan hasil 11.3 


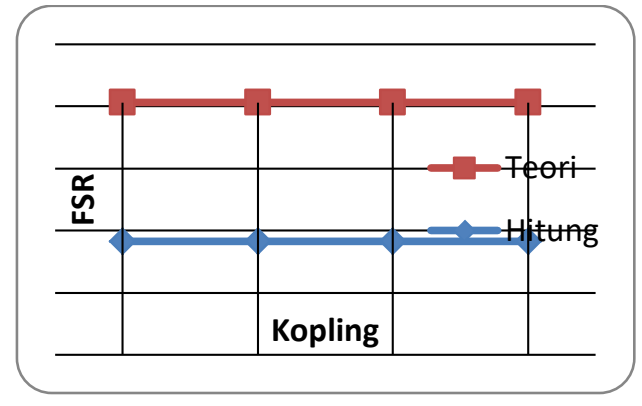

Gambar 5. Hasil FSR dengan panjang gelombang 1350 micrometer

Pada gambar 5 di dapatkan hasil FSR dengan panjang gelombang 1350micrometer ini untuk teori di dapatkan 12.4 untuk hasil hitungan matlab di dapatkan 12.2.

Pada gambar 4 dan 5 dapat di simpulkan untuk memperbesar nilai FSR hanya di butuhkan Panjang gelombang besar. Nilai FSR nantinya akan dapat di gunakan pada Finesse dimana di gunakan untuk mengetahui pengaruh sensitivitas pada sensor optik.

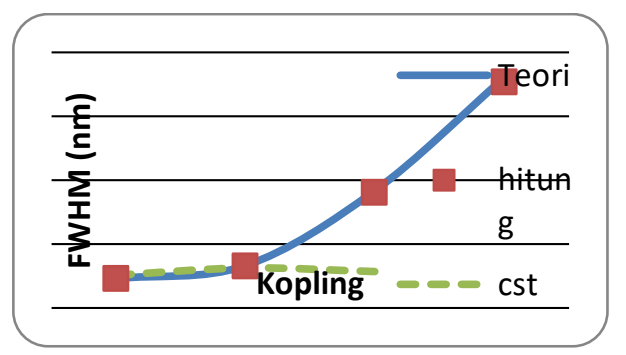

Gambar 6. Variasi Kopling untuk FWHM dengan panjang gelombang 1300 micrometer

Pada gambar 6. Terdapat variasi kopling untuk FWHM ( full Width Half Maximum. pada perhitungan dengan panjang gelombang 1300 micrometer. Hasil paling kecil di dapatkan pada kopling 0.25 dan hasil paling besar di dapatkan padakopling 0.7 tapi sangat di sayangkan untuk FWHM pada aplikasi komersial CST tidak dapat terbaca untuk kopling yang lebih dari 0.5 mikrometer.

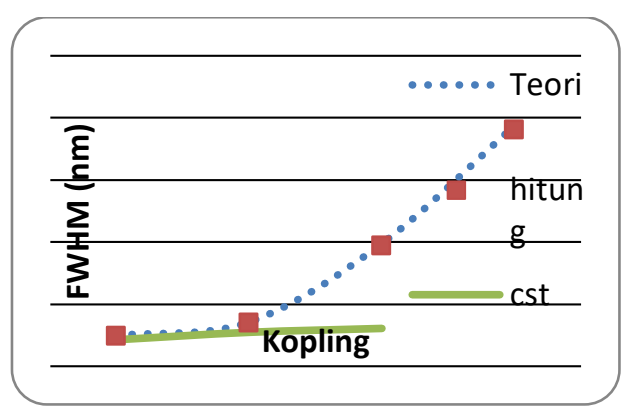

Gambar 7. Variasi Kopling untuk FWHM dengan panjang gelombang 1350 micrometer

Pada gambar 7. Variasi kopling FWHM dengan panjang gelombang 1350 micrometer. Hampir saama dengan panjang gelombang 1300 mikrometer. Hasil terbesar di dapatkan pada kopling 0.7 mikrometer dan hasil terkecil di dapatkan pada kopling 0.25 mikrometer.

Pada gambar 6 dan 7 dapat di simpulkan variasi kopling untuk FWHM sangat berpengaruh semakin besar kopling yang di gunakan maka semakin besar pula FWHM yang di dapatkan. Lebar puncak resonansi terbesar di hasilkan oleh kopling 0.7, pada panjang gelombang 1300 maupun 1350 micrometer dengan nilai 1,35 dan 1,76 pada masingmasing panjang gelombang. 


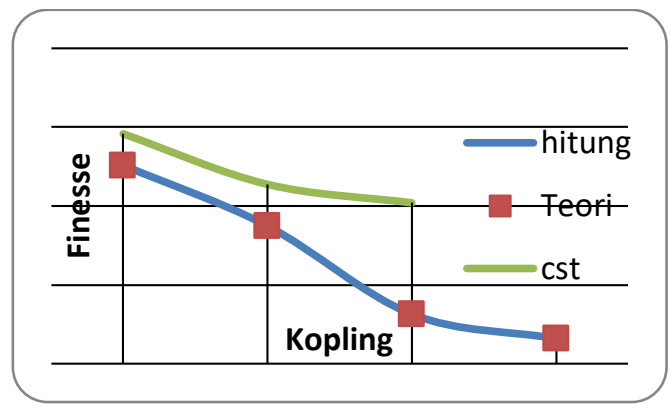

Gambar 8. Finesse hasil untuk panjang gelombang 1350micrometer

Pada gambar 8 . seperti kita ketauhi finese merupakan perbandingan antara FSR dan FWHM. Hasil Finesse pada panjang gelombang 1350 micrometer. Mendapatkan hasil terbaik pada kopling 0.25 mikrometer

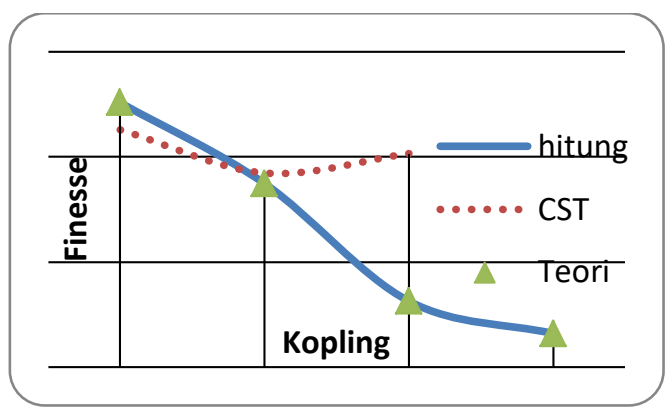

Gambar 9. Finesse hasil untuk panjang gelombang 1300 micrometer

Pada gambar 9 kita merupakan Finesse hasil untuk panjang gelombang 1300 micrometer dapat di lihat sama seperti pada panjang gelombang 1350 mikrometer hasil terbesar di dapatkan pada besar kopling 0.25 mikrometer dan hasil paling kecil terdapat pada panjang kopling 0.7 mikrometer.

Pada persamaan Finesse menggunakan nilai FSR dan FWHM secara bersamaan. Hasil yang di dapat membutuhkan nilai Finesse sebesar mungkin agar baik digunakan dalam sensor optik, hasil Finesse memiliki kesamaan hasil pada panjang gelombang 1300 dan 1350 micrometer tersebut dengan nilai 50.28. Pada Finesse di butuhkan hasil se besar-besarnya agar sensor optik memiliki sensitivitas atau kualitas sensing yang sangat baik. Maka dari itu semakin kecil kopling yang di gunakan semakin baik pula Finesse yang di dapat.

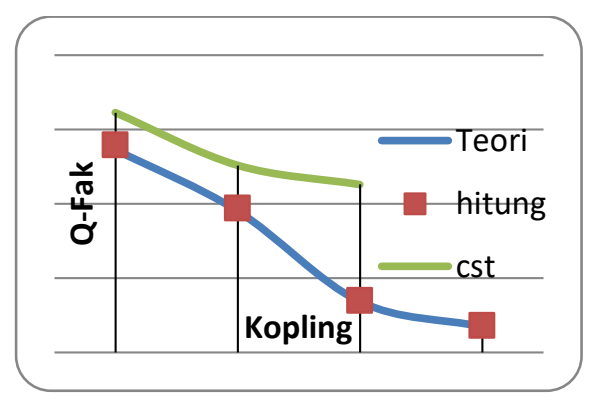

Gambar 10. Nilai Q-Fak dengan variasi kopling. Pada panjang gelombang 1350micrometer

Pada gambar 10. Nilai Q-faktor dengan Variasi kopling pada panjang gelombang 1350 micrometer di dapatkan hasil terbesar pada kopling 0.25 mikrometer dan hasil paling kecil terdapat pada 0.7 mikrometer. Sama halnya seperti percobaan sebelumnya pada kopling 0.7 tidak dapat di hasilkan pada aplikasi komersial CST. Hal ini sangat di sayangkan 


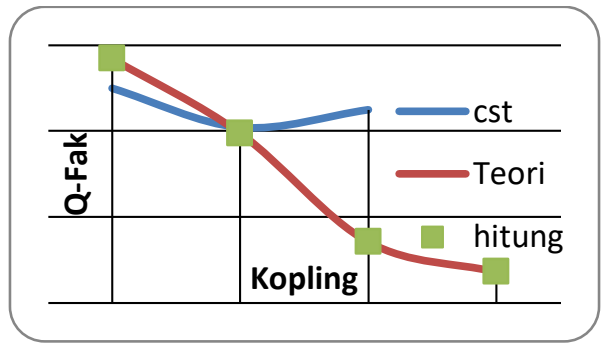

Gambar 11. Nilai Q-fak dengan

Variasi kopling. Pada panjang gelombang 1300micrometer

Pada gambar 11. Nilai Q_fak dengan variasi kopling. Pada panjang gelombang 1300 micrometer. Hasil yang di dapat hampir serupa dengan gambar 10 nilai q-fak dengan variasi kopling pada panjang gelombang 1350 mikrometer. Hasil terbaik di dapatkan dengan besar kopling 0.25 mikrometer dan hasil terkecil di dapatkan pada kopling 0.7 mikrometer

Pada gambar 10 dan 11 dapat di lihat bahwa nilai Q-fak tertinggi terdapat pada kopling 0,25 , baik pada panjang gelombang 1300 maupun 1350 micrometer. Pada panjang gelombang 1300 nilai Q-fak menghasilkan 5786.72 dan pada panjang gelombang 1350 micrometer nilai Q-fak menghasilkan 5572.40.

Untuk Microring Resonator di gunakan sebagai sistem Telekomunikasi Menghasilkan

\begin{tabular}{|c|cccc|}
\hline Pada & \multicolumn{5}{|c|}{ Kopling } \\
Aplikas & \multicolumn{5}{|c|}{ i } & 0.25 & 0.3 & 0.5 & 0.7 \\
\cline { 2 - 5 } & & & & \\
\hline CST & 0.51 & 0.62 & 0.56 & - \\
\hline Matlab & 0.44 & 0.64 & 1.79 & 3.52 \\
\hline Teori & 0.45 & 0.65 & 1.83 & 3.59 \\
\hline
\end{tabular}

Gambar 12. Hasil Bandwith pada panjang gelombang 1.35mikrometer
Gambar 12 merupakan hasil yang di dapat dengan pajang gelombang 1350 mikrometer. Pada hasil bandwith nilai terbesar lah yang sangat berpengaruh karena semakin besar nilai bandwith semakin cepat pula pengiriman dan penerimaan data yang dapat kita gunakan.

\begin{tabular}{|c|cccc|}
\hline \multirow{2}{*}{$\begin{array}{c}\text { Pada } \\
\text { Aplikasi }\end{array}$} & \multicolumn{4}{|c|}{ Kopling } \\
\cline { 2 - 5 } & 0.25 & 0.3 & 0.5 & 0.7 \\
\hline CST & 0.42 & $\mathbf{0 . 5 4}$ & $\mathbf{0 . 6 0}$ & - \\
\hline Matlab & 0.48 & 0.69 & 1.93 & 3.79 \\
\hline Teori & 0.49 & 0.71 & 1.97 & 3.87 \\
\hline
\end{tabular}

Gambar 13.Hasil Bandwith pada panjang gelombang 1300 mikrometer

Pada gambar 13. Hasil bandwith pada panjang gelombang 1300 mikrometer merupakan hasil bandwith yang di butuhkan untuk mempercepat penerimaan dan pengiriman data pada sistem telekomunikasi.

Pada gambar 12 dan 13 dapat kita lihat hasil bandwith terrbesar terjadi pada kopling 0.7 dengan nilai tertinggi pada panjang gelombang 1300 mikrometer ialah 3.59 dan pada panjang gelombang 1350 mikrometer ialah 3.87. semakin besar kopling yang di gunakan maka semakin besar pula bandwith yang di dapat. Semakin besar panjang gelombang yang di gunakan semakin besar pula bandwith yang di dapat.

\section{Simpulan}

$\begin{array}{lrr}\text { Telah } & \text { dilakukan } & \text { pemodelan } \\ \text { Microring } & \text { resonator. } & \text { Variasi }\end{array}$ 
parameter yang di lakukan adalah Kopling. Hasil perhitungan Microring Resonator dengan Variasi Kopling kemudian di bandingkan dengan hasil pada Aplikasi Komersial CST.

Hasil penelitian kali ini di dapatkan nilai FSR sangat baik jika panjang gelombang yang di gunakan besar. Untuk nilai FWHM besar kopling yang di gunakan berpengaruh pada nilai FWHM yang di dapat semakin besar kopling yang di gunakan semakin besar FWHM yang di dapat tetapi nilai FWHM yang di butuhkan ialah sekecil mungkin agar mendapatkan hasil Finesse yang besar. Dengan hasil Finesse yang besar kita dapat mendapatkan sensitivitas sensor yang baik.

Pada perbandingan teori hasil pemodelan matlab dan CST. Dapat kita lihat bahwa hasil dari aplikasi komersial CST hanya dapat di apresiasikan dengan kopling kecil tidak dapat menghitung jika kopling yang di gunakan lebih dari 0.5

\section{Referensi}

1. Anggraeni,(2014),Design and Fabricated Prototype of Planar Optical Waveguide with Polymer, repository.upi.edu, Universitas Pendidikan Indonesia

2. Apriady, D. (2006). Desain dan Fabrikasi Microring-Resonator Sebagai Filter Optik Untuk Jaringan DWDM. Bandung : Institut Teknologi Nasional.

3. Heebner, J. E., Wong,V., Schweinsberg, A., Boyd, R. W., dan Jackson, D.J. (2004).Optical Transmission Characteristics of
Fiber Ring Resonators. IEEE Journal Of Quantum Electronic, Vol.40, No. 6.

4. Hotmariani, Saktioto, Irawan D.(2015),Pemodelan Add-drop Microring Resonator dalam Memperoleh Harga Kecepatan Data dan Daya untuk Sistem Komunikasi Serat Optik, JOM FMIPA Volume 2 No. 1.

5. Isnawati, A. F., Riyanto dan Wijayanti, A. E. (2009). Analisis Jarak TerhadapRedaman, SNR (Signal To Noise Ratio),Dan Kecepatan Download Pada Jaringan ADSL. Purwokerto.

6. Manggolo, I., Marzuki, M., Alaydrus, M. (2011). Optimalisasi Perencanaan Jaringan Akses Serat Optik Fiber To The Home Menggunakan Algoritma Genetika. InComTech, Jurnal Telekomunikasi dan Komputer, Vol.2,No.2.

7. Mohamad A., Bahadoran M., Daud S., Tufail K., Aziz M.S., Jalil M.A., Ali J., (2015). Analysis of Temperature Sensor in All-Pass Microring

Resonator. www.jurnalteknologi.utm.my eISSN 2180-3722

8. Sadegh, A., Alavi, S.E., Mahdaliza, S. (2015). Soliton Coding for Secured Optical Communication Link. SpringerBriefs in Applied Sciences and Technology

9. Song J., Luo X., Tu X., Park M K., Kee J S., Zhang J., Yu M.,Lo G.,and Kwong D. (2014) , 
Electrical tracing-assisted dualmicroring label-free optical bio/chemical sensors, Optics Express Vol. 20

10. Syah, H.S.D., Ajulian, A. (2014). Penarikan Jaringan Baru FTTH ODC-SMT-FQ hingga ODP-SMT-FQ.Semarang : Universitas Diponegoro 